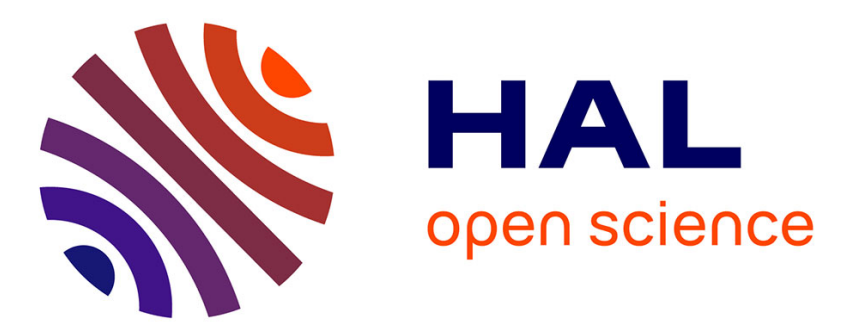

\title{
Pressure-Induced Structural transformations of the Zintl phase sodium silicide
}

Raul Quesada Cabrera, Ashkan Salamat, Oleg I. Barkalov, Olivier Leynaud, Peter T. Hutchins, Dominik Daisenberger, Denis Machon, Andrea Sella, Dewi W. Lewis, Paul F. Mcmillan

\section{To cite this version:}

Raul Quesada Cabrera, Ashkan Salamat, Oleg I. Barkalov, Olivier Leynaud, Peter T. Hutchins, et al.. Pressure-Induced Structural transformations of the Zintl phase sodium silicide. Journal of Solid State Chemistry, 2009, 182 (9), pp.2535-2542. 10.1016/j.jssc.2009.06.037 . hal-00993262

\section{HAL Id: hal-00993262 https://hal.science/hal-00993262}

Submitted on 19 May 2014

HAL is a multi-disciplinary open access archive for the deposit and dissemination of scientific research documents, whether they are published or not. The documents may come from teaching and research institutions in France or abroad, or from public or private research centers.
L'archive ouverte pluridisciplinaire HAL, est destinée au dépôt et à la diffusion de documents scientifiques de niveau recherche, publiés ou non, émanant des établissements d'enseignement et de recherche français ou étrangers, des laboratoires publics ou privés. 


\title{
Pressure-Induced Structural Transformations of the Zintl Phase Sodium Silicide
}

Raúl Quesada Cabrera ${ }^{a}$, Ashkan Salamat ${ }^{a}$, Oleg I. Barkalov ${ }^{\mathrm{a}}$, Olivier Leynaud ${ }^{\mathrm{b}}$, Peter Hutchins ${ }^{\mathrm{a}}$, Dominik Daisenberger ${ }^{\mathrm{a}}$, Denis Machon ${ }^{\mathrm{c}}$, Andrea Sella ${ }^{\mathrm{a}}$, Dewi W. Lewis ${ }^{\mathrm{a}}$, Paul F. McMillan ${ }^{\mathrm{a}}$

${ }^{a}$ Department of Chemistry and Materials Chemistry Centre, Christopher Ingold Laboratories, University College London, 20 Gordon Street, London WC1H OAJ, United Kingdom

${ }^{b}$ Department of Crystallography, Birkbeck College, Malet Street, London WC1E 7HX, United Kingdom

${ }^{c}$ LPMCN, Universite Lyon-I, Batiment Leon Brillouin, 43 Bld du 11 novembre 1918, 69622 Villeurbanne, Lyon, France

* To whom correspondence should be addressed: p.f.mcmillan@ucl.ac.uk (fax: +44 (0)20 76797463$)$

\begin{abstract}
The high-pressure behaviour of $\mathrm{NaSi}$ is studied using Raman spectroscopy and angle-dispersive synchrotron X-ray diffraction to observe the onset of structural phase transformations and potential oligomerisation into anionic Si nanoclusters with extended dimensionality. Our studies reveal a first structural transformation occurring at 8-10 GPa, followed by irreversible amorphisation above $15 \mathrm{GPa}$, suggesting the formation of $\mathrm{Si}-\mathrm{Si}$ bonds with oxidation of the $\mathrm{Si}^{-}$species and reduction of $\mathrm{Na}^{+}$to metallic sodium. We have combined our experimental studies with DFT calculations to assist in the analysis of the structural behaviour of $\mathrm{NaSi}$ at high pressure.
\end{abstract}

\section{Keywords}

Sodium silicide, Zintl phase, high pressure transition, synchrotron X-ray diffraction, pressure induced amorphisation, Raman spectroscopy, density functional calculation

\section{Introduction}

Alkali and alkaline earth silicides and germanides belong to the family of Zintl phases, in which polyanionic species, formed of the tetrelide atoms counterbalance the electropositive metal cations [1-3]. These compounds are interesting because the $\mathrm{Si}$ and $\mathrm{Ge}$ atoms occur with negative oxidation states and low coordination numbers, and they form unusual low-dimensional structures such as sheets, chains or isolated polyhedra. They are also important precursors for the synthesis of bulk amorphous semiconductors, including Si nanoparticles prepared by solution-phase routes or in the solid state [4], and also the expanded framework solids known as semiconductor clathrates that are isotypic with ice clathrate hydrates [5-7]. There are two main features of interest for high-pressure studies of Zintl phases containing anionic $\mathrm{Si}_{\mathrm{n}}{ }^{\mathrm{z}-}$ units. First, the application of high pressure might cause a change of connectivity via redistribution of the $\mathrm{Si}-\mathrm{Si}$ bonds within the anionic framework. Second, $\mathrm{Si}^{-}$oxidation reactions might occur resulting in additional $\mathrm{Si}-\mathrm{Si}$ bond formation with corresponding reduction of $\mathrm{Na}^{+}$and elimination of the elemental sodium $\left(\mathrm{Na}^{0}\right)$. Either of these outcomes would result in a new family of methods for producing $\mathrm{Si}_{\mathrm{n}}$ clusters and nanoparticles with unusual coordination states, polymerisation and electronic properties, via solid state processing at low temperatures.

The alkali metal monosilicides and monogermanides ( $\mathrm{MSi}$, MGe) structures have been described previously [8-10]. The larger alkali silicides ( $\mathrm{KSi}, \mathrm{RbSi}, \mathrm{CsSi}$ ) exhibit a cubic arrangement of $\left[\mathrm{Si}_{4}\right]^{4-}$ tetrahedra and alkali metal cations, with space group $P \overline{4} 3$ n. Sodium silicide (NaSi) crystallises with a monoclinic structure (space group $c 2 / c$ ) containing isolated $\left[\mathrm{Si}_{4}\right]^{4-}$ tetrahedra surrounded by $\mathrm{Na}^{+}$ions (Fig. 1) $[8,9]$. The $\left[\mathrm{Si}_{4}\right]^{4-}$ anions present in the structure are analogous to the $\mathrm{P}_{4}$ groups found in white phosphorus, reflecting the fact that $\mathrm{Si}^{-}$is isoelectronic with $\mathrm{P}$. By contrast, lithium silicide (LiSi) has a different structure to the other alkali metal silicides, in that the pyramidal 3-coordinated Si atoms are connected to provide alternating zig-zag chains, analogous to one of the black, high-pressure structures of phosphorus (Fig. 1).

1 Permanent address: Institute of Solid State Physics, Russian Academy of Sciences, 142432 Chernogolovka, Moscow District, Russia. 
Earlier studies aimed to prepare new alkali metal silicide or germanide compounds synthesised at highpressure and high-temperature conditions followed by quenching to ambient conditions for analysis of the structures [11-16]. However, no high-density structural modifications have been reported for NaSi so far. Here we describe the low-temperature compression of $\mathrm{NaSi}$ and the recovery of the resulting amorphous/nanocrystalline materials to ambient conditions.

\section{Experimental}

$\mathrm{NaSi}$ is highly reactive to moisture, and therefore all syntheses and DAC loading experiments were carried out in either a Schlenk vacuum line or a glove box with $\mathrm{H}_{2} \mathrm{O} / \mathrm{O}_{2}$ content typically of less than 1 ppm. For NaSi syntheses from sodium and silicon, a $15 \%$ excess of $\mathrm{Na}$ metal (about 5at.\%) was added to counteract loss due to evaporation and reaction with the inner surface of the reaction vessel. The elements were placed together in a $\mathrm{Ni}$ crucible and placed inside a steel autoclave fitted with a screw top and annealed $\mathrm{Cu}$ gasket [17]. The sealed autoclave was placed inside a furnace for 30-40 hours at $650^{\circ} \mathrm{C}$. After the reaction was complete, the autoclave was opened inside a dry-box. The sample was crashed in a mortar and placed in into the Pyrex glass cylinder. The cylinder was mounted in the vacuum system in order to remove the excess of $\mathrm{Na}$ from the sample using the turbomolecular pump $\left(10^{-6} \mathrm{mbar}, 240^{\circ} \mathrm{C}\right.$ for 15-20 hours). The sample was checked by X-ray diffraction using a Stoe diffractometer $\left(\mathrm{CuK} \alpha_{1}\right.$ radiation). The diffraction patterns indicated that complete reaction to form NaSi had occurred [9] (Fig. 2).

NaSi samples were loaded into the DAC in a glove box, prior to the high-pressure experiments. The diamond culet faces were typically $300 \mu \mathrm{m}$ in diameter, and $80 \mu \mathrm{m}$-diameter holes were drilled in preindented rhenium gaskets (30-50 $\mu \mathrm{m}$ indent thickness) to contain the sample. Raman experiments were carried out using a mechanically-driven opposed 4-screw symmetric diamond anvil cell [18]. Synchrotron $\mathrm{x}$-ray diffraction studies were carried out using a $\mathrm{N}_{2}$-driven membrane cell from Diacell (now EasyLab). No pressure-transmitting medium was added to avoid potential reactions with the sample. Ruby chips were added for pressure measurement by the ruby fluorescence method [19]. The narrow width of the ruby fluorescence peaks indicated approximately hydrostatic pressure conditions below $10 \mathrm{GPa}$. Above this pressure the ruby lines became broadened, but differences in the pressure indicated by different ruby chips within the sample chamber did not exceed $2 \mathrm{GPa}$.

The in-house Raman system at UCL consisted of a high-throughput optical system based on Kaiser supernotch filters, an Acton spectrograph and a liquid- $\mathrm{N}_{2}$ cooled back-thinned CCD detector. Spectra were excited using the $514.5 \mathrm{~nm}$ line of an $\mathrm{Ar}^{+}$laser focused onto the sample using a 50x long working distance Mitutoyo objective (numerical aperture $=0.42$ ). Raman scattering was collected in $180^{\circ}$ geometry through the same lens. The laser power was maintained at $\sim 1 \mathrm{~mW}$ to avoid excessive heating of the sample. Subsequent data analysis and peak fitting were carried out using the PeakFit v4 software. Angledispersive X-ray diffraction data were collected at the UK Synchrotron Radiation Source (SRS, Daresbury Laboratory, station 9.5HP). Two-dimensional X-ray patterns were obtained and then integrated around the diffraction rings and converted into 1D plots using the FIT2D software [20]. FullProf [21] was used with the WinPlotr GUI interface [22] to carry out LeBail and Rietveld analyses of the data. The known structure of $\mathrm{NaSi}$ at ambient pressure and temperature conditions was used as a starting model for refining the high pressure structures. Cell parameters were first approximately refined manually before performing subsequent LeBail and Rietveld refinements. Further Rietveld refinements of the high pressure structures were also performed using the DFT calculated results as starting models.

Initial DFT optimisations were performed using the $\mathrm{DMol}^{3}$ code with a double numeric basis set and the PWC functional [23, 24]. The unit cell parameters were fixed at the initial values suggested from refinements of the experimental data and the atom positions optimised. We then undertook an initial series of compressions and expansions around these initial cell sizes to explore the potential energy surface (those results are not reported here, but are available from the authors on request). In each case, the cell was compressed (or expanded) by $5 \%$ along each cell dimension, initially with a fixed $\beta$ angle and then by scanning the angle in steps of $5^{\circ}$. These studies were carried out to provide suitable starting geometries for the subsequent full structural optimisations. In order to achieve these, the CASTEP code was used, with ultrasoft norm-conserving pseudopotentials, the PWC functional and a plane-wave cut-off of $330 \mathrm{eV}$ [25]. Each structure was fully optimised (cell parameters and atomic positions) with a specified applied external pressure. We considered two starting geometries obtained from the (constant volume) $\mathrm{DMol}^{3}$ calculations: one obtained starting from the ambient pressure experimental unit cell (with a 
monoclinic angle of $117^{\circ}$ ), and another obtained from the high pressure phase, where we found a local minimum with a monoclinic angle of $105^{\circ}$. The first model was fully optimised under applied external pressures ranging from $0 \mathrm{GPa}$ to $40 \mathrm{GPa}$, and the second was fully optimised over a more limited sample of the pressure range.

\section{Results}

\subsection{Raman spectroscopy}

The isolated $\mathrm{Si}_{4}{ }^{4-}$ anion is isostructural with the $\mathrm{P}_{4}$ molecule and exhibits $T_{d}$ point group symmetry ( $\left.\overline{4} 3 \mathrm{~m}\right)$. The vibrational modes of the cluster anion and their Raman (R) or infrared (IR) activities are $A_{l}(R)+E$ $(R)+T_{2}(R, I R)$. The $A_{l}$ mode corresponds to a symmetric breathing vibration of the tetrahedral molecule, the $E$ mode is a doubly degenerate symmetric deformation, and the $T_{2}$ vibration involves both stretching and bending components. These modes give rise to three peaks of approximately equal intensity at 474$482 \mathrm{~cm}^{-1}\left(A_{1}\right), 351-356 \mathrm{~cm}^{-1}\left(T_{2}\right)$, and $285 \mathrm{~cm}^{-1}(E)$ in the Raman spectra of the solid silicides with cubic symmetry, $\mathrm{CsSi}, \mathrm{K}_{3} \mathrm{LiSi}_{4}$ and $\mathrm{K}_{7} \mathrm{LiSi}_{8}$ [26]. In these materials, the $\mathrm{Si}_{4}{ }^{4-}$ groups are slightly distorted from tetrahedral symmetry, and this gives rise to weak additional peaks and small splitting of the main bands. Lattice modes and vibrations associated with the heavy metal cations occur at low frequency below 150 $\mathrm{cm}^{-1}$, although it has been suggested that $\mathrm{Li}^{+}$cations may contribute to the higher frequency modes for $\mathrm{K}_{3} \mathrm{LiSi}_{4}$ and $\mathrm{K}_{7} \mathrm{LiSi}_{8}$ samples [26].

The Raman spectrum for $\mathrm{NaSi}$ at ambient conditions is quite different from those of the other alkali monosilicides (Fig. 3). The strong $A_{l}$ mode is easily recognised at $480 \mathrm{~cm}^{-1}$; however, the $E$ mode is split to give a pair of medium intensity peaks at 280 and $300 \mathrm{~cm}^{-1}$, and the $T_{2}$ mode gives rise to a group of three peaks centred near $350 \mathrm{~cm}^{-1}$. This is a result of the site distortion of the $\mathrm{Si}_{4}{ }^{4-}$ anions within the monoclinic crystal structure. Carrying out a symmetry analysis for the $C 2 / c$ structure (point group $C_{2 h}$ ) with $\mathrm{Z}=8 \mathrm{Na}_{4} \mathrm{Si}_{4}$ units in the equivalent primitive cell leads to a prediction of $\Gamma_{\text {normal }}=12 A_{g}+12 A_{u}+$ $12 B_{g}+12 B_{u}$, where the $A_{g}$ and $B_{g}$ species are Raman active. Each $\mathrm{Si}_{4}{ }^{4-}$ unit is associated to 3 internal modes, $v_{1}\left(480 \mathrm{~cm}^{-1}\right), v_{2}\left(280 \mathrm{~cm}^{-1}\right)$ and $\mathrm{v}_{3}\left(350 \mathrm{~cm}^{-1}\right)$ and 6 external modes ( 3 rotations and 3 translations). In our Raman spectra, we expect 6 bands associated to the internal modes: 1 around $480 \mathrm{~cm}^{-}$ ${ }^{1}$ ), 2 around $280 \mathrm{~cm}^{-1}$ and 3 around $350 \mathrm{~cm}^{-1}$. Rotations and translations are expected at low wavenumbers and only a few are often observed with our spectrometer. This is also the case for the modes related to translation of $\mathrm{Na}$ atoms $\left(6 \mathrm{~A}_{\mathrm{g}}+6 \mathrm{~A}_{\mathrm{u}}+6 \mathrm{~B}_{\mathrm{g}}+6 \mathrm{~B}_{\mathrm{u}}\right)$.

During the first compression steps, changes in the Raman spectra indicate how the sample accommodates to pressure in non-hydrostatic conditions. This is evidenced by the appearance of two modes at 350 and $185 \mathrm{~cm}^{-1}$ at $4 \mathrm{GPa}$ (Fig. 3). However, noticeable structural transformations occurring within the $\mathrm{Si}_{4}{ }^{4-}$ units during compression result in a rapid increase in the intensity of a band near $370 \mathrm{~cm}^{-1}$, in the region of the $\mathrm{T}_{2}$ vibration, above $8 \mathrm{GPa}$. This observation coincides with a reduction in the number of peaks observed in the spectrum. Both changes are consistent with a transition into a phase with higher symmetry. The spectral features of crystalline NaSi remain recognisable up to $23 \mathrm{GPa}$. However, further compression results in a dramatic broadening of all modes, indicating pressure-induced amorphisation (Fig. 3). The onset of the amorphisation process is preceded by a noticeable reduction in intensity of the $\mathrm{Si}_{4}{ }^{4-}$ stretching and bending vibrations, suggesting that the amorphisation may be associated with changes in the $\mathrm{Si}-\mathrm{Si}$ bonding. During further compression to $50 \mathrm{GPa}$ the Raman scattering signal from the sample consists of a broad featureless signal extending to above $600 \mathrm{~cm}^{-1}$ that could barely be distinguished from the background (Fig. 3).

On examination of the Raman data at elevated pressures (Fig. 4), a linear increase of about $4 \mathrm{~cm}^{-1} \mathrm{GPa}^{-1}$ is observed for most modes up to $8 \mathrm{GPa}$. The Si-Si stretching mode at $482 \mathrm{~cm}^{-1}$ is the most resistant to compression, with a coefficient of $2.81 \mathrm{~cm}^{-1} \mathrm{GPa}^{-1}$. Between 8 and $12 \mathrm{GPa}$, some of the lattice and vibrational modes show a small shift to lower wavenumber. The softening is largest in the case of the $A_{l}$ and $E$ symmetry modes: $-3.24 \mathrm{~cm}^{-1} \mathrm{GPa}^{-1}$ and $-4.71 \mathrm{~cm}^{-1} \mathrm{GPa}^{-1}$ respectively and it indicates the occurrence of a phase transition. The transformation is fully reversible upon decompression but it occurs with some hysteresis, indicating a first order transition (Fig. 4). A second vibrational mode softening at around $15 \mathrm{GPa}$ suggests the initiation of the pressure-induced amorphisation observed. This will be explained and confirmed by our X-ray diffraction results.

During decompression from $50 \mathrm{GPa}$ (Fig. 5), the sample remained mainly amorphous with a broad maximum near $470 \mathrm{~cm}^{-1}$ at $1 \mathrm{GPa}$. Some regions of the sample probed within the cell exhibited broad 
features that are similar (but not identical) to Raman bands reported for metastable silicon phases such as $\mathrm{Si}$-III [27]. It is not known whether the partial metastable recrystallisation occurs spontaneously during decompression or whether it is due to the laser irradiation.

Once the sample was recovered to ambient conditions and the DAC opened, a vigorous reaction with atmospheric $\mathrm{O}_{2}$ or $\mathrm{H}_{2} \mathrm{O}$ took place, either with the highly reactive amorphous $\mathrm{NaSi}$ phase or with perhaps nanocrystalline $\mathrm{Na}$ metal produced during the amorphisation process.

\section{$3.2 X$-ray diffraction studies and density functional theory calculations.}

Our Raman studies were complemented with in situ X-ray diffraction. Upon initial compression, all the peaks are observed to broaden due both to internal strains developed at grain boundaries (in the absence of a pressure transmitting medium) within the compressed polycrystalline sample, and also the 1-2 GPa pressure gradients, indicated by the different ruby chips placed within the sample chamber (Fig. 6). The monoclinic NaSi structure remains recognisable up to about $8 \mathrm{GPa}$ (Fig. 6). Changes in the pressure variation of individual reflections reveal evidence for a structural or phase transformation occurring in the 8-12 GPa range (Fig. 7). The new diffraction pattern is dominated by two strong reflections at 2.4 and 2.9 $\AA \quad\left(2 \theta=10.6^{\circ}\right.$ and $\left.11.9^{\circ}\right)$ at $14 \mathrm{GPa}$. Substantial peak broadening did not allow an accurate structural refinement of the high-pressure solid, so we carried out DFT calculations in order to obtain models to be used in our LeBail and Rietveld refinements.

The calculated cell volume matched that obtained by LeBail extraction (Fig. 8). Changes in the tetrahedral Si-Si distances and angles calculated upon compression are also shown in Fig. 8. Our initial constrained minimizations indicated that, as the cell was compressed, the monoclinic angle would be reduced. Full optimisation of the approximate high-pressure phase at $12 \mathrm{GPa}$ resulted in a structure with $\beta$ $=106^{\circ}$, compared with $\beta=120^{\circ}$ at ambient conditions. This structure is close to one obtained by taking the ambient phase and re-optimising it at an applied pressure of $\mathrm{P}=12 \mathrm{GPa}$. However, that optimization was not successful if the high pressure condition was applied in a single step: the pressure must be increased gradually in steps of $\sim 2 \mathrm{GPa}$ from the ambient phase to achieve an optimised high pressure structure. That result indicates the presence of an energy barrier in the system that is likely associated with a first order phase transition into a high pressure NaSi phase. One example of a Rietveld refinement using the calculated structure of $\mathrm{NaSi}$ at $12 \mathrm{GPa}$ as a starting model is shown in Fig. 9. Experimental and calculated cell and atomic parameters are given in Table 2. The observed data (dots) fit quite well with the calculated curve (line), with reliability factors of $R_{p}=9.21, R_{w p}=10.9, R_{\text {exp }}=2.27$ and the Bragg $R$ factor $=2.20$.

Diffraction evidence for pressure-induced amorphisation (PIA) of the sample as recorded by the Raman scattering measurements is shown by peak broadening and disappearance of most of the diffraction peaks beyond $\sim 15 \mathrm{GPa}$. Although this pressure is much lower than that determined for the onset of PIA in the Raman experiments, this is not surprising in view of the longer correlation length required for crystalline X-ray diffraction features to be observed. The diffraction pattern corresponding to the amorphous modification is dominated by a single broad reflection. The initiation of PIA in the X-ray diffraction data indicates that the onset of the amorphisation process is associated with loss of long range order beginning at $15 \mathrm{GPa}$ but the Raman data indicate that the local order of the $\left[\mathrm{Si}_{4}\right]^{4-}$ units is maintained until $23 \mathrm{GPa}$. No recrystallisation of the amorphous modification occurs during further pressurisation to $50 \mathrm{GPa}$ (Fig. 7). On decompression, it was possible to follow a continuous shift in the position of the broad amorphous reflection down to nearly ambient pressure, but the diffraction pattern changed abruptly in the last stages just before opening the DAC, with the appearance of two very weak broad reflections at 2.3 and $3.7 \AA^{-1}$ that are reminiscent of the pattern produced by amorphous silicon [28] (Fig. 10). We carried out a further experiment at high pressure using $\mathrm{CO}_{2}$ laser heating in the diamond anvil cell to anneal the amorphous sample held at $30 \mathrm{GPa}$. To our surprise, this resulted in the appearance of sharp crystalline peaks due to bcc $\mathrm{Na}$ metal (Fig. 11). However, the broad features of the amorphous $\mathrm{Na}_{1-\mathrm{x}} \mathrm{Si}$ material remained in the patterns.

\section{Discussion}

The ambient pressure structure of $\mathrm{NaSi}$ is analogous to that of white phosphorus that forms a bodycentered cubic lattice with discrete $\mathrm{P}_{4}$ tetrahedra with intra-tetrahedral P-P distances of $2.21 \AA$ [29]. The black orthorhombic modification that is analogous to the $\mathrm{Si}$ sublattice arrangement in LiSi is formed by puckered layers of phosphorus atoms, with P-P distances of 2.22 and $2.24 \AA$ within the same layer, which 
fall within the same range as in the white modification [30, 31]. The longest Si-Si bonds in the threedimensional LiSi structure are at around 2.4-2.5 $\AA$, which are shorter than the first-nearest neighbour distance between tetrahedra calculated in this study for $\mathrm{NaSi}$ at $15 \mathrm{GPa}(3.39 \AA)$. The latter result indicates it is unlikely that the high pressure transition observed for $\mathrm{NaSi}$ is simply a transformation into a LiSi-related three-dimensional network. Instead, our experimental results and calculations suggest that the two $\mathrm{NaSi}$ structures are related through a translation of the $\left[\mathrm{Si}_{4}\right]^{4-}$ tetrahedral layers accompanied by a rearrangement of the $\mathrm{Na}^{+}$positions and a relaxation of the $\left[\mathrm{Si}_{4}\right]^{4-}$ tetrahedra towards a more highly symmetric structure (Fig. 12).

It has been reported that $\mathrm{NaGe}$, which is also monoclinic at ambient conditions, undergoes a phase transition into the tetragonal $\mathrm{NaPb}$ structure at $4 \mathrm{GPa}$ and $700{ }^{\circ} \mathrm{C}$ [13]. This structure contains isolated $\left[\mathrm{Si}_{4}\right]^{4-}$ tetrahedral anions and it is also adopted by the cubic alkali monosilicides and monogermanides containing large cations $(\mathrm{K}, \mathrm{Rb}, \mathrm{Cs})$ at conditions around $4 \mathrm{GPa}$ and $600-700^{\circ} \mathrm{C}$ [16]. However, the Rietveld refinements carried out using the $\mathrm{NaPb}$ structure as a starting model did not fit the diffraction patterns accurately and the minimum value for the monoclinic $\beta$-angle in NaSi was calculated to be $106^{\circ}$.

The formation of the amorphous $\left(\mathrm{Na}_{1-\mathrm{x}} \mathrm{Si}\right)$ material at high pressure is an intriguing observation. The featureless Raman spectra and broad X-ray diffraction pattern resemble those recorded for the metallic high-density amorphous phase (HDA) of elemental a-Si [28, 32, 33]. It is therefore possible that a highdensity metallic amorphous form of $\mathrm{NaSi}$ has been produced in our experiments. Such an amorphous phase could contain a mixture of separated $\mathrm{Si}_{4}{ }^{4-}$ units as well as tetrahedra linked by $\mathrm{Si}$-Si bonds, by analogy with those that occur among varieties of "red" phosphorus. However, the appearance of diffraction peaks due to metallic $\mathrm{Na}$ following heating experiments at high pressure indicates that redox reactions can occur, producing $\mathrm{Na}^{0}$ by $\mathrm{Na}^{+}+\mathrm{e}^{-}$. The corresponding oxidation of silicon species involves $\mathrm{Si}^{-}=\mathrm{Si}^{\mathrm{o}}+\mathrm{e}^{-}$, with the formation of new $\mathrm{Si}-\mathrm{Si}$ bonds. The result is a progressive cross-linking of the silicide network to form nanoclusters of partially polymerised $\left(\mathrm{Si}_{\mathrm{x}}\right)^{\mathrm{y}-}$ units, that can contain both $\mathrm{Si}(\mathrm{Si})_{3}$ and $\mathrm{Si}(\mathrm{Si})_{4}$ sites. These could have interesting and unusual electronic and optical properties. High pressure treatment of alkali metal silicides may provide a new route to synthesise and control the polymerisation state of silicon-based nanoclusters.

Our results also have implications for the occurrence of high-density/low-density (HDA, LDA) polyamorphic transitions in Si- and Ge-based systems [28, 32-35]. Amorphous $\mathrm{Si}$ and $\mathrm{Ge}$ are known to undergo a semiconductor-metallic transformation at high pressure that maps on to an expected densitydriven liquid-liquid phase transition that appears quite general among elemental and other simple liquids [36]. It is interesting to explore how the observed PIA in NaSi and other alkali metal-containing alloys and compounds relate to the HDA-LDA behaviour. Recently, Machon et al. [37] studied amorphisation of the semiconductor clathrate phase $\mathrm{Rb}_{6} \mathrm{Si}_{46}$, and suggested that the large $\mathrm{Rb}$ atoms remain trapped within the a-Si structure at high pressure. They indicated that the high-density amorphous structure resembled that of HDA a-Si, and that a polyamorphic transition to an LDA phase resembling a-Si occurred during decompression. Our diffraction data indicate that the situation for $\mathrm{NaSi}$ is different, and that chemical diffusion accompanied by $\mathrm{Na}^{+} / \mathrm{Na}^{0}$ and $\mathrm{Si}^{-} / \mathrm{Si}^{0}$ redox processes occurs at high pressure or during decompression. In contrast to $\mathrm{Rb}$, the smaller $\mathrm{Na}$ atoms appear to diffuse more easily through an a-Si network; as occurs during the formation of Si clathrates from the thermal decomposition of $\mathrm{NaSi}$ [38]. We expect that nanocrystalline $b c c \mathrm{Na}$ may form readily at high pressure causing the production of new $\mathrm{Si}-\mathrm{Si}$ bonds between $\left[\mathrm{Si}_{4}\right]^{4-}$ units and forming nanoscale clusters. Our computational studies indicate that the amorphisation process could originate in the ready distortion of the tetrahedral $\left[\mathrm{Si}_{4}\right]^{4-}$ groups, indicated by our vibrational spectroscopy results at high pressure.

Consideration of the molar volumes gives useful insights into the nature of the chemical processes occurring in these systems. Under ambient conditions, the molar volume of $\mathrm{NaSi}$ is calculated to be 29.34 $\mathrm{cm}^{3} \mathrm{~mol}^{-1}$, whereas the sum of the molar volumes of elemental $\mathrm{Na}$ and $\mathrm{Si}$ is $35.74 \mathrm{~cm}^{3} / \mathrm{mol}$. When the pressure is increased to $15 \mathrm{GPa}$, the molar volume calculated for NaSi decreases to $20.69 \mathrm{~cm}^{3} \mathrm{~mol}^{-1}$. At this pressure, the volume of $\mathrm{Na}$ metal is $12.05 \mathrm{~cm}^{3} \mathrm{~mol}^{-1}$ [39]. On the other hand, under these conditions, silicon can exist in either of three possible phases: in its high-density amorphous (HDA) modification, as the $\beta$-Sn type, or simple hexagonal $(s h)$ phase. The molar volumes for $\beta$-Sn and $s h$-Si are known to be 20.36 [40] and 20.15 [41] $\mathrm{cm}^{3} \mathrm{~mol}^{-1}$ respectively. The molar volume of HDA-Si, however, is unknown, but must be smaller than that of LDA-Si, $24.36 \mathrm{~cm}^{3} \mathrm{~mol}^{-1}$ [42]. What this implies is that the molar volume of $\mathrm{NaSi}$ at $15 \mathrm{GPa}$ must be slightly greater than the sum of volumes of its elemental components, a situation that therefore favours the otherwise unexpected decomposition of the intermetallic to its elements upon compression. Furthermore, we note that diffraction peaks of sodium become visible, 
whereas no evidence is observed for crystalline silicon. This is in stark contrast to our previous experiments in which $\beta$-Sn Si crystallizes spontaneously in the X-ray beam at $17 \mathrm{GPa}$ and suggests that the presence of sodium may play a role in suppressing crystallization, thereby extending the stability range of the amorphous silicon.

\section{Conclusions}

We have described the high-pressure behaviour of NaSi up to $50 \mathrm{GPa}$. As evidenced by both Raman and X-ray diffraction results, the solid adopts a higher-symmetry crystal structure in the range between 8-12 GPa. Density functional theory calculations showed that the ambient and high-pressure crystal structures are related by slipping of the planes of Si tetrahedra and rearrangement of the Na atoms. No evidence of a transformation of $\mathrm{NaSi}$ into a crystalline non-molecular network was recorded. However, random crosslinking between $\mathrm{Si}$ subunits has been suggested to result in irreversible loss of translational order. The nature of this amorphous modification has been discussed in terms of pressure-induced decomposition of the sample.

\section{Acknowledgements}

This work was supported by EPSRC Portfolio grant EP/D504782 (To C.R.A. Catlow, P. Barnes and PFM) and an EPSRC Senior Research Fellowship (GR/T00757) to PFM. Computer resource provided by EPSRC grant GR/S84415/01 (DWL). OIB also acknowledges support of Marie Curie Incoming International Fellowship (Project title "High-pressure phase transitions in polyamorphic systems of semiconducting elements", contract number MIF2-CT-2006-008575). We thank A. Lennie (SRS Daresbury Laboratory, CCLRC) for assistance with the synchrotron experiments. 


\section{References}

[1] S.M. Kauzlarich, Chemistry, Structure, and Bonding of Zintl Phases and Ions, Wiley-VCH Publishers, New York, 1996.

[2] R. Schäfer, Annu. Rev. Mater. Sci. 15 (1985) 1-41.

[3] R. Schäfer, Angew. Chem., Int. Ed. 12 (1973) 694-712.

[4] P.F. McMillan, J. Gryko, C. Bull, R. Arledge, A.J. Kenyon, B.A. Cressey, J. Solid State Chem. 178 (2005) 937-949.

[5] J.S. Kasper, P. Hagenmuller, M. Pouchard, C. Cros, Science 150 (1965) 1713-1714.

[6] A. San-Miguel, P. Toulemonde, High Pressure Res. 25 (2005) 159-185.

[7] G.K. Ramachandran, J. Dong, J. Diefenbacher, J. Gryko, R.F. Marzke, O.F. Sankey, P.F. McMillan, J. Solid State Chem. 145 (1999) 716-730.

[8] R. Schäfer, W. Klemm, Z. Anorg. Allg. Chem. 312 (1961) 214-220.

[9] J. Witte, H.G. Schnering, Z. Anorg. Allg. Chem. 327 (1964) 260-273.

[10] E. Busmann, Z. Anorg. Allg. Chem. 313 (1961) 90-106.

[11] J. Evers, G. Oehlinger, G. Sextl, Angew. Chem., Int. Ed. 32, (1993) 1442-1444.

[12] J. Evers, G. Oehlinger, G. Sextl, H-O. Becker, Angew. Chem., Int. Ed. 26 (1987) 76-78.

[13] J. Evers, G. Oehlinger, G. Sextl, A. Weiss, Angew. Chem., Int. Ed. 24 (1985) 500-501.

[14] J. Evers, G. Oehlinger, A. Weiss, J. Solid State Chem. 20 (1977) 173-181.

[15] J. Evers, G. Oehlinger, A. Weiss, Angew. Chem., Int. Ed. 17 (1978) 538-539.

[16] J. Evers, G. Oehlinger, G. Sextl, A. Weiss, Angew. Chem., Int. Ed. 23 (1984) 528-529.

[17] E. Hohmann, Z. Anorg. Chemie, 257 (1948) 113-126.

[18] H.K. Mao, G. Shen, R.J. Hemley, T.S. Duffy, in: M. H. Manghnani, T. Yagi (Ed.), X-ray diffraction with a double hot-plate laser-heated diamond cell, Properties of Earth and Planetary Materials at High Pressure and Temperature, American Geophysical Union, Washington DC, 1998, p. 27-34.

[19] R.A. Forman, G.J. Piermarini, J.D. Barnett, S. Block, Science 176 (1972) 284-285.

[20] A.P. Hammersley, S.O. Svensson, M. Hanfland, A.N. Fitch, D. Häusermann, High Pressure Res. 14 (1996) 235-248.

[21] J. Rodríguez-Carvajal, FULLPROF: A Program for Rietveld Refinement and pattern matching analysis, Abstracts of the Satellite Meeting on Powder Diffraction of the XV Congress of the IUCr, Toulouse, 1990, p. 127.

[22] T. Roisnel, J. Rodríguez-Carvajal, in: R. Delhez, E.J. Mittenmeijer (Ed.), WinPLOTR: A Windows tool for powder diffraction patterns analysis, Materials Science Forum, Proceedings of the Seventh European Powder Diffraction Conference (EPDIC 7), 2000, p. 118-123.

[23] $\mathrm{DMol}^{3}$ Software, Accelrys, Inc., San Diego, CA. 2006.

[24] J. Perdew, Y. Wang, Phys. Rev. B: Condens. Matter Mater. Phys. 46 (1992) 12947-12954.

[25] S.J. Clark, M.D. Segall, C.J. Pickard, P.J. Hasnip, M.I.J. Probert, K. Refson, M.C. Payne, Z. Kristallog. 220 (2005) 567-570.

[26] G. Kliche, M. Schwarz, H.G. Schnering, Angew. Chem., Int. Ed. 26 (1987) 349-351.

[27] M. Hanfland, K. Syassen, High Pressure Res. 3 (1990) 242-244.

[28] D. Daisenberger, M. Wilson, P.F. McMillan, R. Quesada Cabrera, M.C. Wilding, D. Machon, Phys. Rev. B: Condens. Matter Mater. Phys. 75 (2007) 224118.1-224118.11

[29] D.E.C. Corbridge, E.J. Lowe, Nature 170 (1952) 629.

[30] R. Hultgren, N.S. Gingrich, B.E. Warren, J. Chem. Phys. 3 (1935) 351-355.

[31] A. Brown, S. Rundqvist, Acta Cryst. 19 (1965) 684-685.

[32] S.K. Deb, M. Wilding, M. Somayazulu, P.F. McMillan, Nature. 414 (2001) 528-530.

[33] P.F. McMillan, M. Wilson, D. Daisenberger, D. Machon, Nat. Mater. 4 (2005) 680-684.

[34] E. Principi, A. Di Cicco, F. Decremps, A. Polian, S. De Panfilis, A. Filipponi, Phys. Rev. B: Condens. Matter Mater. Phys. 69 (2004) 201201.1-201201.4

[35] F. Coppari, A. Di Cicco, A. Congeduti, J.C. Chervin, F. Baudelet, A. Polian, High Pressure Res. 29 (2009) 103-107.

[36] P.F. McMillan, J. Mater. Chem. 14 (2004) 1506-1512.

[37] D. Machon, P. Toulemonde, P.F. McMillan, M. Amboage Castro, A. Muñoz, P. RodriguezHernandez, A. San Miguel, Phys. Rev. B: Condens. Matter Mater. Phys. (accepted)

[38] A. San-Miguel, P. Kéghélian, X. Blase, P. Mélinon, A. Pérez, J.P. Itié, A. Polian, E. Reny, C. Cros, M. Pouchard, Phys. Rev. Lett. 83 (1999) 5290-5293.

[39] M. Hanfland, I. Loa, K. Syassen, Phys. Rev. B: Condens. Matter Mater. Phys. 65 (2002) 184109.1184109.8

[40] A. Werner, J.A. Sanjurjo, M. Cardona, Solid State Commun. 44 (1982) 155-158. 
[41] J.Z. Hu, L.D. Merkle, C.S. Menoni, I.L. Spain, Phys. Rev. B: Condens. Matter. Mater. Phys. 34 (1986) 4679-4684.

[42] J.S. Custer, M.O. Thompson, D.C. Jacobson, J.M. Poate, S. Rooda, W.C. Sinke, F. Spaepen, Appl. Phys. Lett. 64 (1994) 437-439. 
(a)

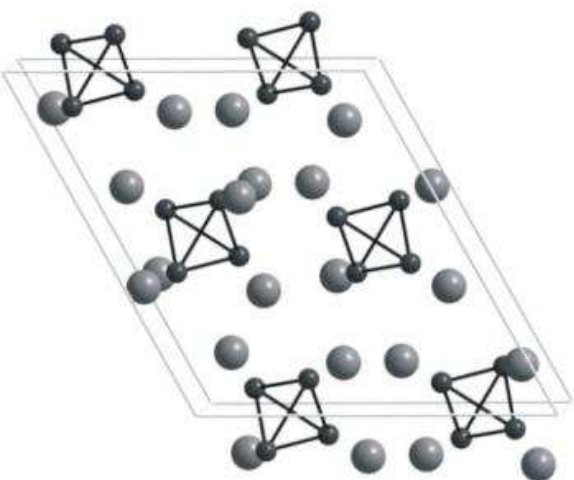

(b)

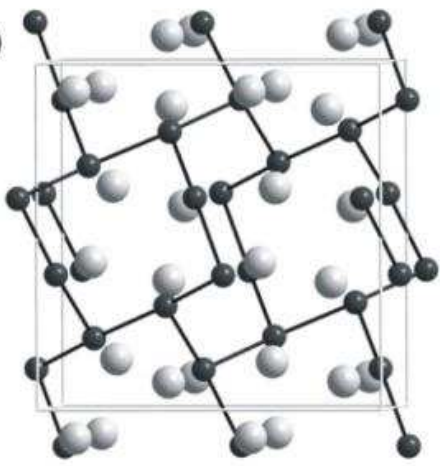

Fig. 1. (a) Representation of the crystal structure of $\mathrm{NaSi}$ at ambient pressure. $\mathrm{NaSi}$ is isoelectronic with white phosphorus, containing $\left[\mathrm{Si}_{4}{ }_{4}^{4}\right]$ ions arranged in isolated distorted tetrahedra. (b) The crystal structure of LiSi at ambient pressure, related to black phosphorus Cmca structure, is formed by three-fold coordinated $\mathrm{Si}^{-}$anions arranged along chains, forming eight-membered rings.

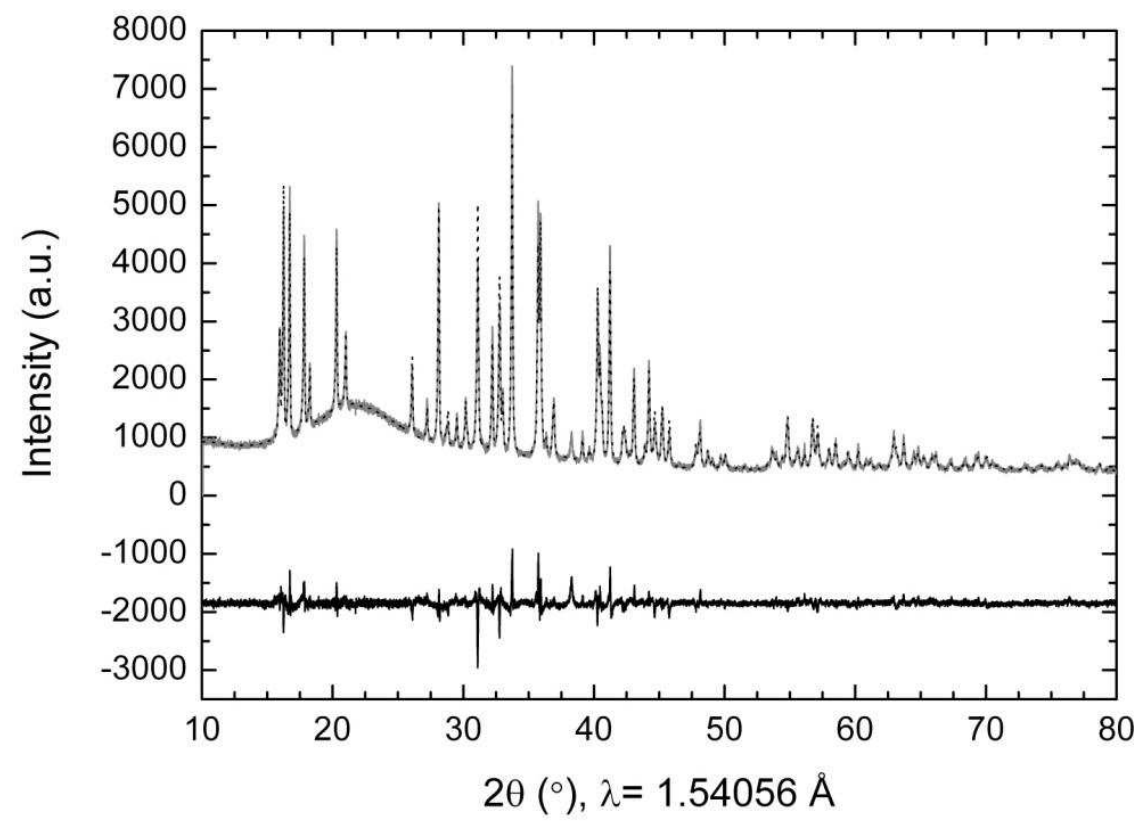

Fig. 2. X-ray diffraction pattern obtained at ambient conditions after the synthesis of NaSi. Rietveld refinement confirms the monoclinic $C 2 / c$ structure. Reliability factors are $\mathrm{R}_{\mathrm{p}}=16.1, \mathrm{R}_{\mathrm{wp}}=16.0, \mathrm{R}_{\mathrm{exp}}=$ 8.58, Bragg R-factor $=3.56$. 


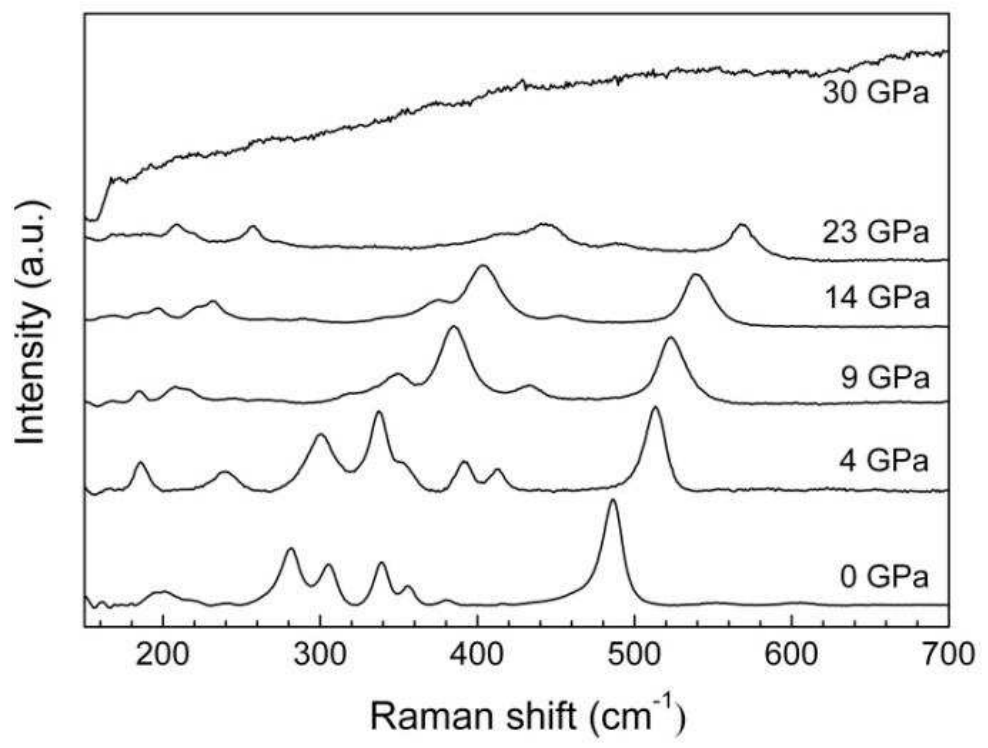

Fig. 3. Raman spectra of NaSi upon compression at room temperature. The distortion of $\mathrm{Si}_{4}{ }^{4-}$ groups in the $C 2 / c$ structure gives rise to Raman-active vibrational bands at $480 \mathrm{~cm}^{-1}\left(A_{1}\right), 280$ and $300 \mathrm{~cm}^{-1}(E)$ and $339.5,355.7$ and $380.5 \mathrm{~cm}^{-1}\left(T_{2}\right)$ at normal pressure. The spectra suddenly changes above $8 \mathrm{GPa}$ in the region of the $T_{2}$ vibration, with a rapid increase in the intensity of a band around $370 \mathrm{~cm}^{-1}$. Above 23 $\mathrm{GPa}$, we observed irreversible broadening of all modes.
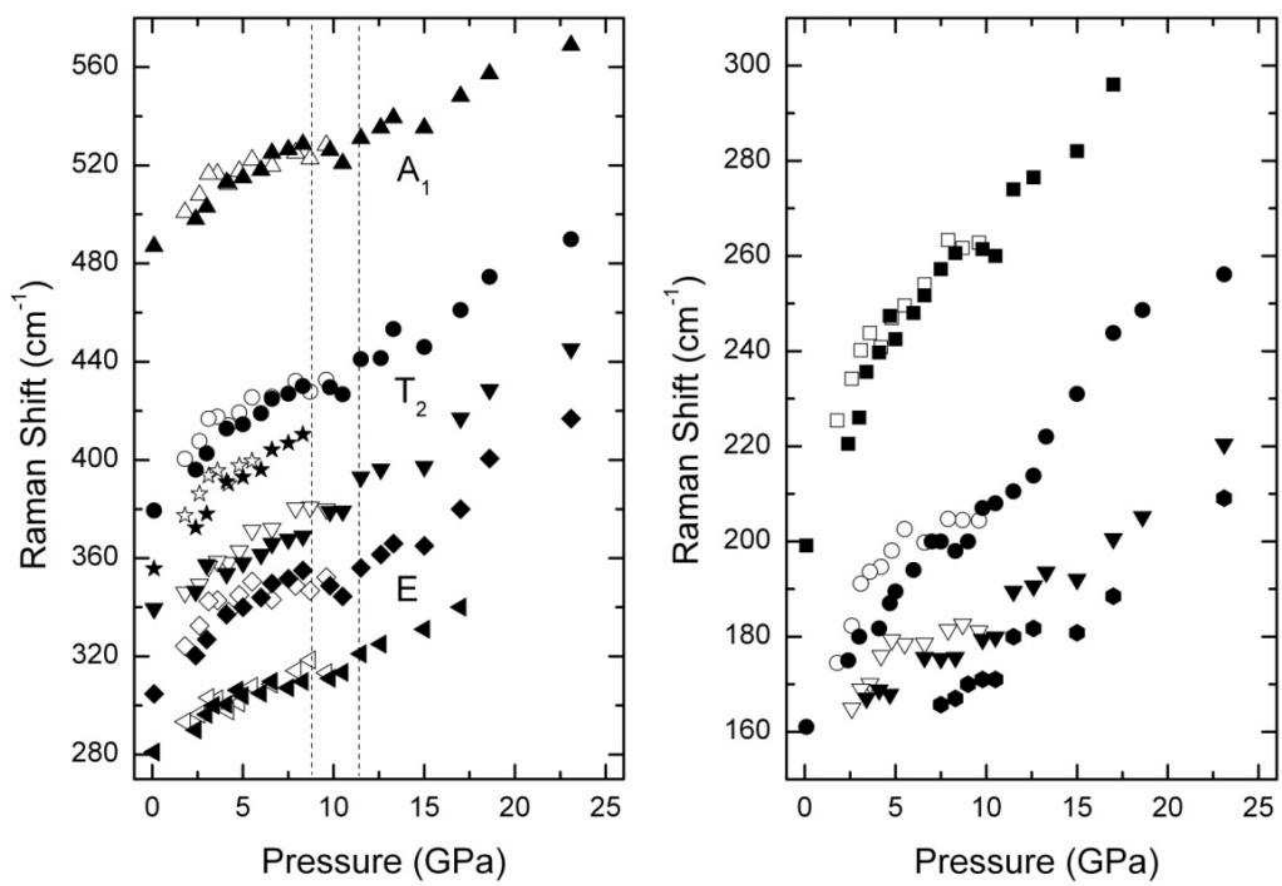

Fig. 4. Raman shifts plotted vs pressure for crystalline NaSi. Full and empty symbols stand for compression and decompression runs respectively. Softening of certain bands is observed in between 8$12 \mathrm{GPa}$ (highlighted). A further red-shift is observed in some modes at $15 \mathrm{GPa}$. 


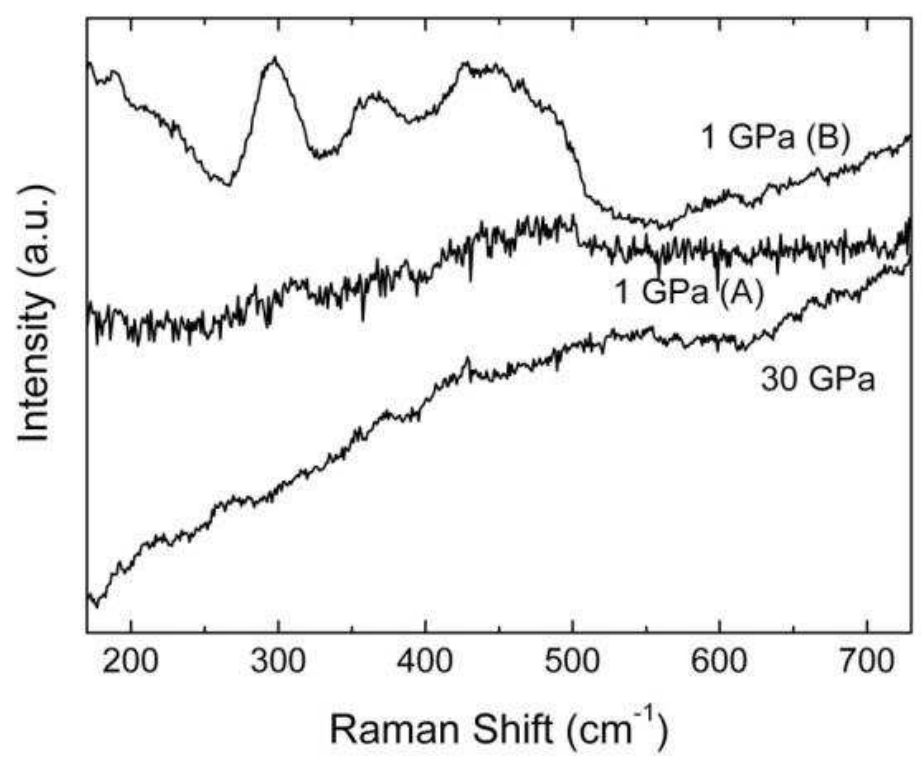

Fig. 5. Raman spectra of the amorphous sample obtained in the diamond anvil cell at $30 \mathrm{GPa}$ and following decompression to $1 \mathrm{GPa}$. Two different spectra were obtained from regions of the sample recovered to $1 \mathrm{GPa}$. Spectra (A) and (B) correspond to different spots across the sample in the DAC.

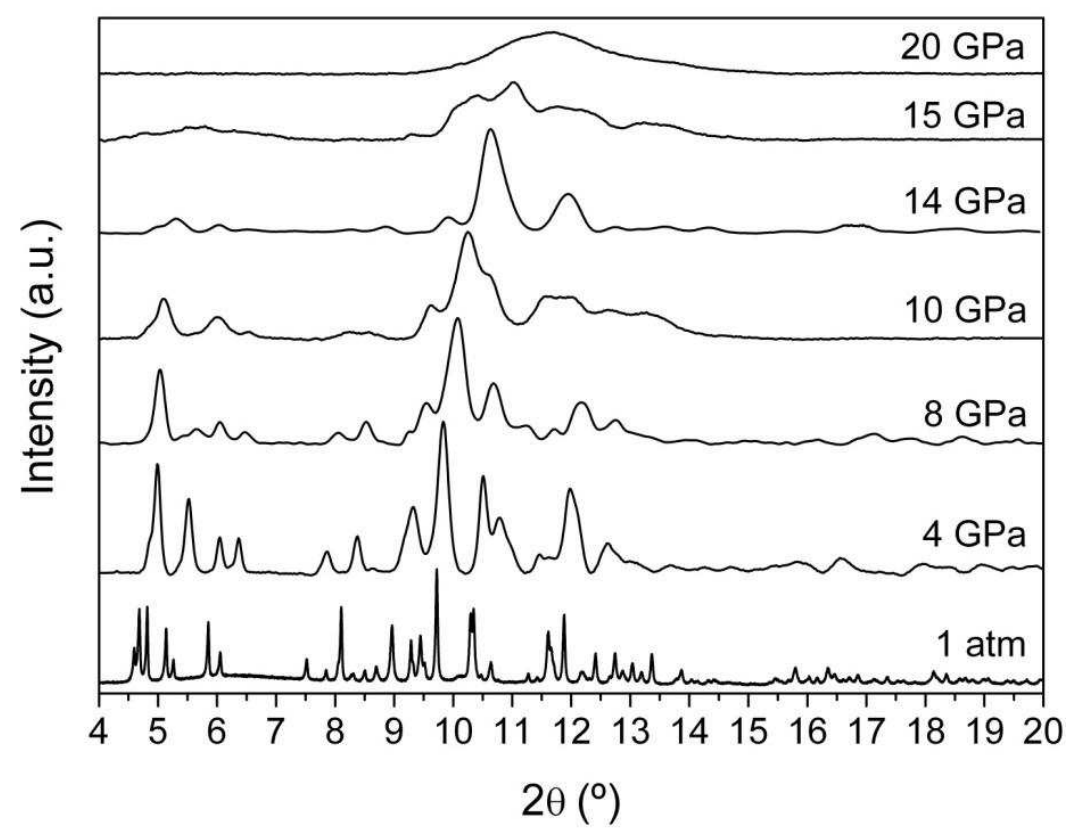

Fig. 6. Synchrotron X-ray diffraction patterns on NaSi upon compression at room temperature. The pattern at 1 atm was obtained using a Stoe diffractometer $\left(\mathrm{CuK} \alpha_{1}\right)$, however, it has been calculated for the synchrotron radiation at SRS 9.5HP $(\lambda=0.443970 \AA)$ to be compared with the patterns at high pressure. A first crystal-to-crystal transformation of $\mathrm{NaSi}$ is observed above $8 \mathrm{GPa}$ followed by pressure-induced amorphisation of the sample at $15 \mathrm{GPa}$. 


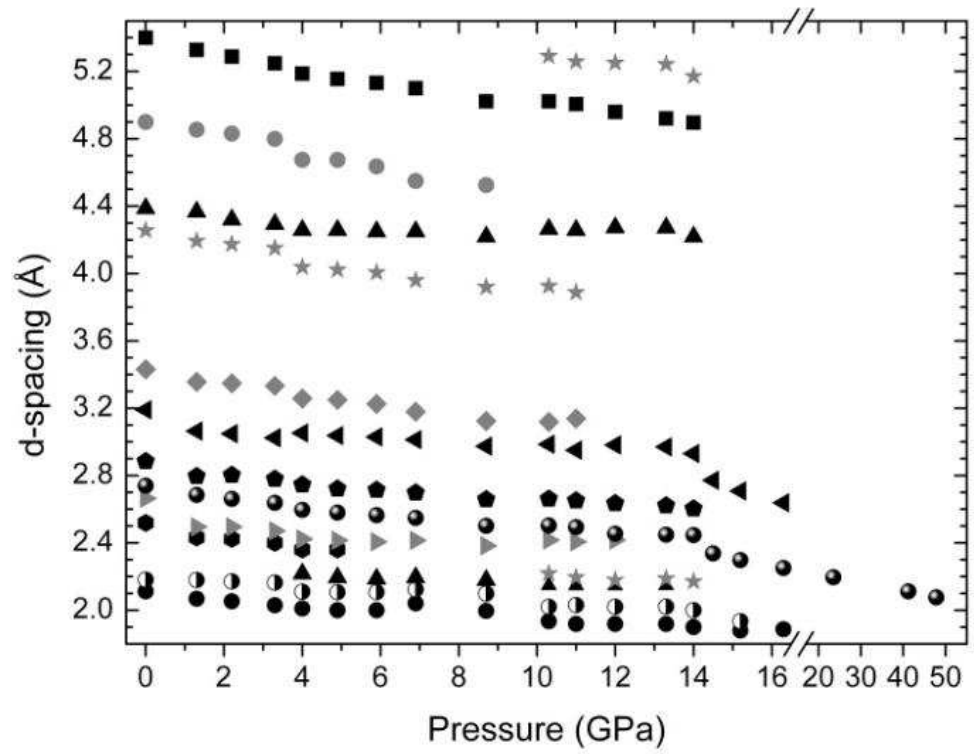

Fig. 7. Variation of interplanar spacings $(d)$ of NaSi upon compression. The transformation occurring between 8 and $12 \mathrm{GPa}$ is highlighted by grey symbols.
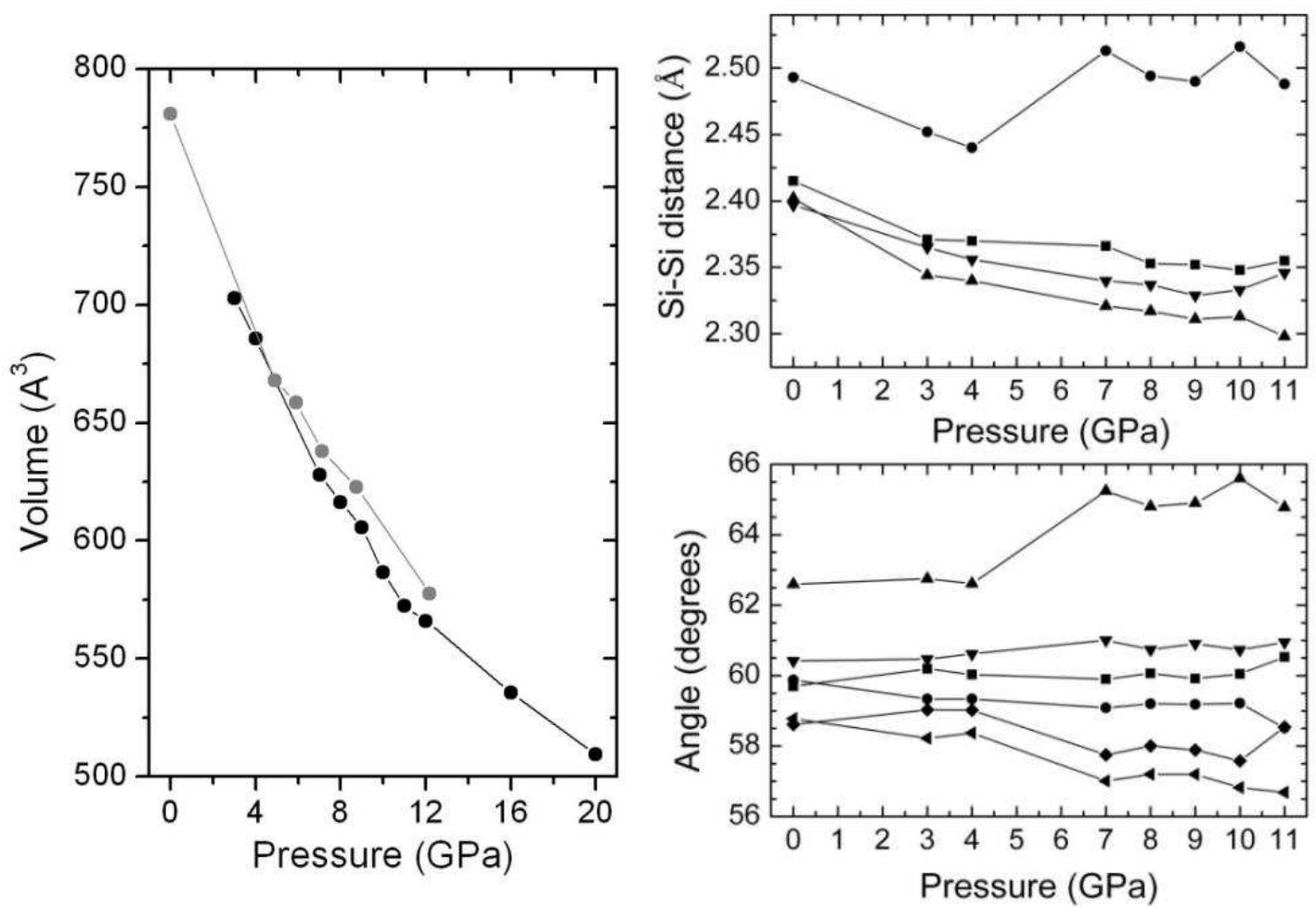

Fig. 8. Experimental (grey symbols) and calculated (black symbols) changes in unit cell volume as a function of pressure (left). Changes with pressure in $\mathrm{Si}-\mathrm{Si}$ distances and angles calculated for $\left[\mathrm{Si}_{4}\right]^{4-}$ tetrahedra in the NaSi structure during compression (right). 


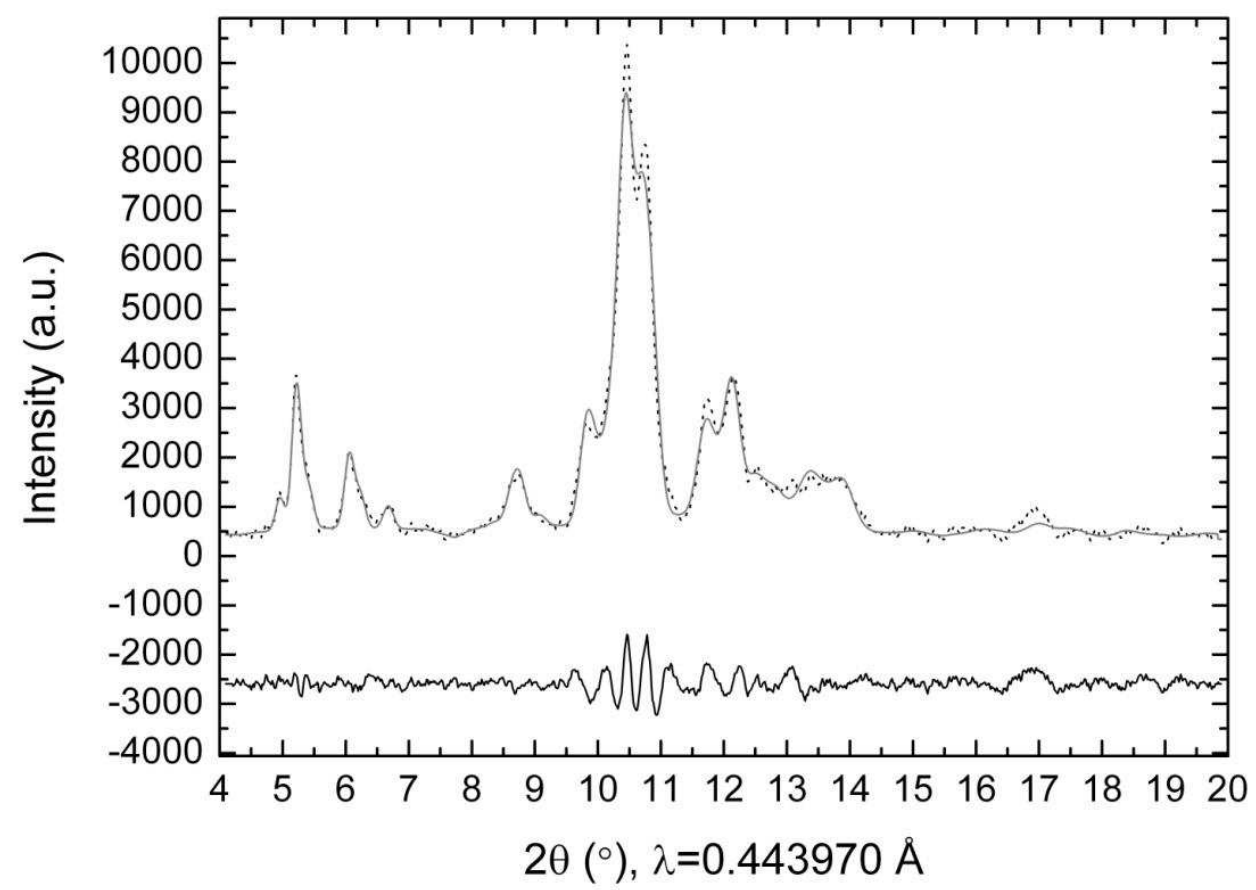

Fig. 9. Rietveld refinement carried out for an X-ray diffraction pattern of the high-pressure phase of NaSi at $12 \mathrm{GPa}(\lambda=0.443970 \AA$ ). The NaSi $C 2 / c$ structure calculated at $16 \mathrm{GPa}$ was used as a reference model for the refinement. Reliability factors are $\mathrm{R}_{\mathrm{p}}=9.21, \mathrm{R}_{\mathrm{wp}}=10.9, \mathrm{R}_{\mathrm{exp}}=2.27$, Bragg $\mathrm{R}$-factor $=2.20$. 

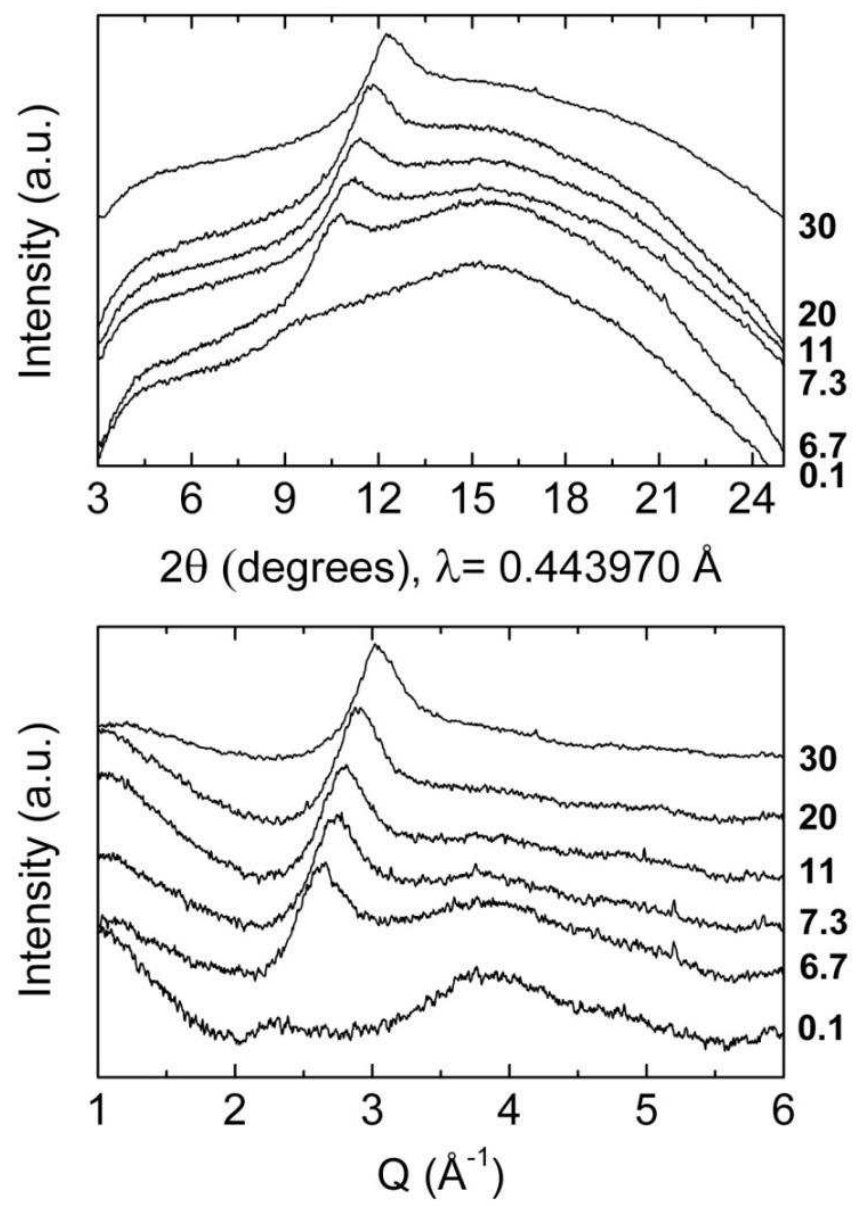

Fig. 10. X-ray diffraction patterns of NaSi obtained upon decompression from $30 \mathrm{GPa}$. Raw data (above) and corresponding baseline-subtracted data in $\mathrm{Q}$ space (below). A pattern of a-Si will be included here if Dominik agrees with it.

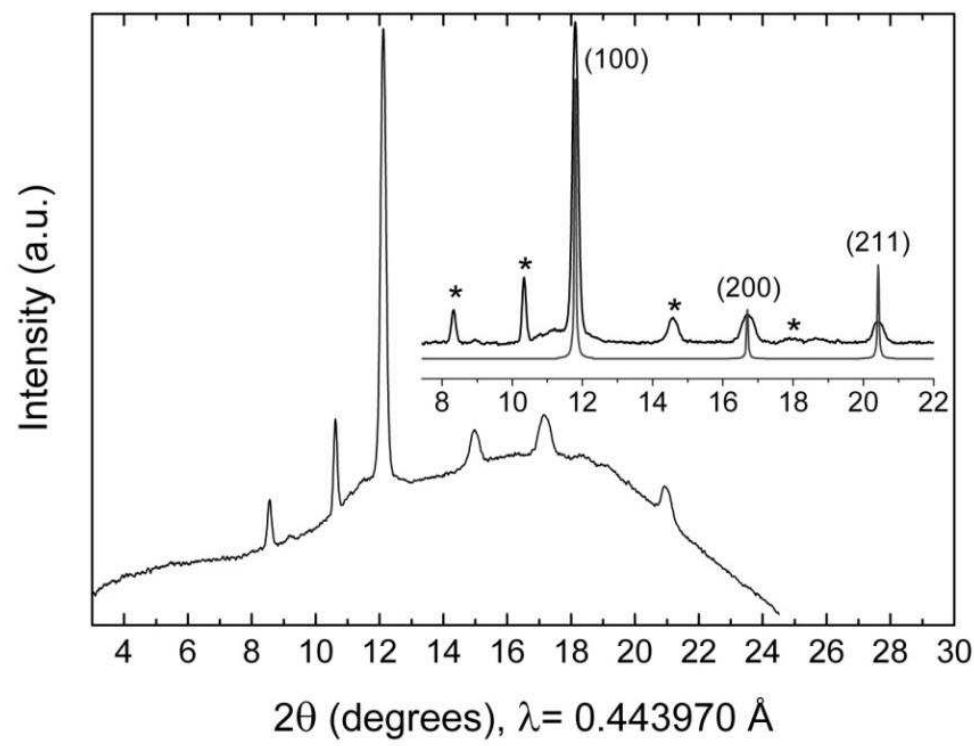

Fig. 11. X-ray diffraction pattern obtained after laser annealing of the amorphous NaSi sample at $30 \mathrm{GPa}$. The sample was loaded in dried $\mathrm{NaCl}$ and heated indirectly with a $\mathrm{CO}_{2}$ laser, using ruby chips to transmit heat to the sample. The inset shows the pattern obtained after baseline subtraction, with characteristic lines from $b c c$ Na metal (100), (200) and (211) reflections (grey line) and peaks corresponding to the B2 phase of $\mathrm{NaCl}$ used as the pressure-transmitting medium (marked by asteriks). 


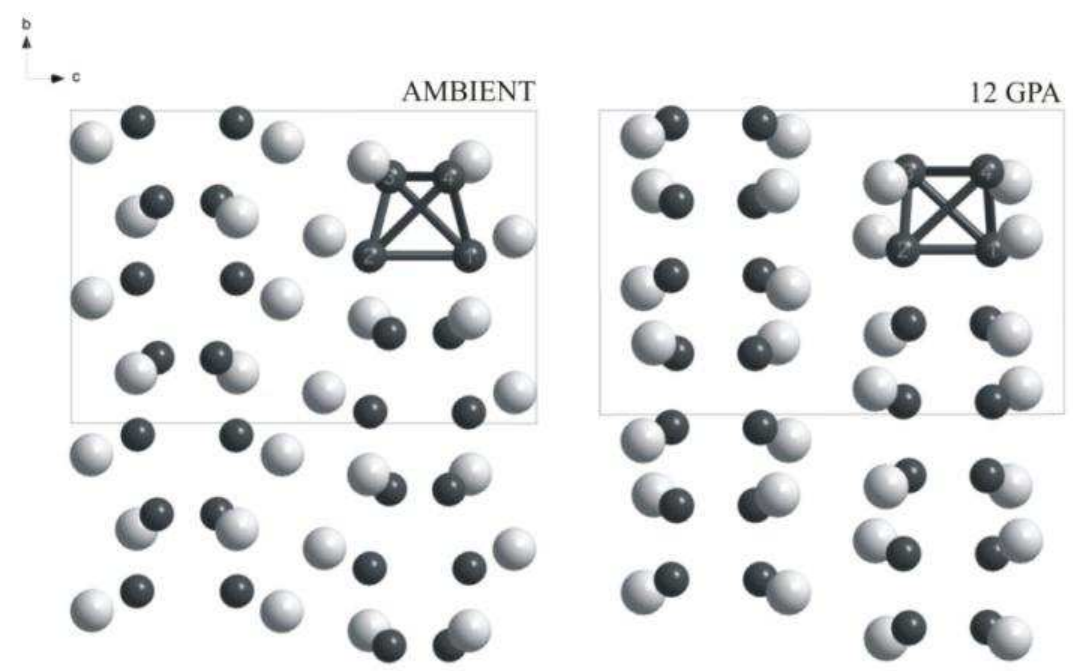

Fig. 12. Representation of the crystal structure of NaSi at ambient and high pressure (view along [100] plane). The structures are related by a slip of the $\left[\mathrm{Si}_{4}\right]^{4-}$ tetrahedral layers along with a rearrangement of the $\mathrm{Na}^{+}$cations and reduced distortion of the $\left[\mathrm{Si}_{4}\right]^{4-}$ units.

Table 1. Correlation analysis for $\mathrm{NaSi}$. There are three internal modes for each $\mathrm{Si}_{4}$ group, $\mathrm{v}_{1}(482 \mathrm{~cm}-1)$, $\mathrm{v}_{2}(285 \mathrm{~cm}-1)$ and $\mathrm{v}_{3}(356 \mathrm{~cm}-1)$ and 6 external modes (3 rotations and 3 translations). $\mathrm{A}_{\mathrm{g}}$ and $\mathrm{B}_{\mathrm{g}}$ are Raman active.

\begin{tabular}{|c|c|c|c|c|c|}
\hline & hoven & & $\mathrm{G}_{\mathrm{M}} \rightarrow \mathrm{G}_{\mathrm{S}}$ & $\mathrm{G}_{\mathrm{F}}$ & \\
\hline Transl. & Libr & Int. & $\mathbf{T}_{\mathrm{d}} \quad \mathbf{C}_{2}$ & $\mathrm{C}_{2 \mathrm{~h}}$ & \\
\hline $\mathrm{Si}_{4}$ & & & & & \\
\hline & 1 & 1 & $\begin{array}{l}\mathrm{E} \\
\mathrm{T}_{1}<\end{array}$ & $B_{g}$ & $\begin{array}{l}2 v_{3}, 2 \text { lib., 2trans. } \\
v_{1}, 2 v_{2}, v_{3}, \text { lib., trans. }\end{array}$ \\
\hline 1 & & 1 & $\mathrm{~T}_{2}$ & $B_{u}$ & $2 v_{3}, 2$ lib., 2 trans. \\
\hline $\mathrm{Na}(1)$ & d Na & & & & \\
\hline & & & & & $\begin{array}{l}6 \text { trans. } \\
6 \text { trans. }\end{array}$ \\
\hline & & & & & $\begin{array}{l}6 \text { trans. } \\
6 \text { trans. }\end{array}$ \\
\hline
\end{tabular}


Table 2. Experimental and calculated cell parameters and atomic positions for $\mathrm{NaSi}$ at high pressure.

\begin{tabular}{|c|c|c|c|c|c|c|}
\hline \multicolumn{7}{|c|}{ Cell Parameters } \\
\hline & DFT & Exp. & Err. & & & \\
\hline a & 9.62272 & 10.18991 & 0.00846 & & & \\
\hline b & 6.08230 & 6.07541 & 0.00479 & & & \\
\hline c & 9.62272 & 9.96378 & 0.00739 & & & \\
\hline$\alpha$ & 90.00000 & 90.00000 & 0.00000 & & & \\
\hline$\beta$ & 105.76357 & 109.38072 & 0.04078 & & & \\
\hline$\gamma$ & 90.00000 & 90.00000 & 0.00000 & & & \\
\hline \multicolumn{7}{|c|}{ Atomic positions } \\
\hline & DFT & & & Ref. & & \\
\hline & $\mathrm{x}$ & $\mathrm{y}$ & $\mathrm{z}$ & $\mathrm{x}$ & $\mathrm{y}$ & $\mathrm{z}$ \\
\hline $\mathrm{Na}(1)$ & 0.11991 & -0.76442 & -0.38827 & $0.12336(3)$ & $-0.80632(2)$ & $-0.37622(2)$ \\
\hline $\mathrm{Na}(2)$ & 0.82457 & -0.58583 & -0.40665 & $0.84174(2)$ & $-0.55910(2)$ & $-0.42675(1)$ \\
\hline $\mathrm{Si}(1)$ & 0.11334 & -1.04175 & -0.15849 & $0.10155(1)$ & $-1.04640(2)$ & $-0.13803(1)$ \\
\hline $\mathrm{Si}(2)$ & -0.07563 & -1.30006 & -0.16588 & $-0.08363(1)$ & $-1.31807(2)$ & $-0.16523(1)$ \\
\hline
\end{tabular}

